\title{
IMAGINÁRIO DE MÃES ACERCA DA HOSPITALIZAÇÃO DO FILHO NA UNIDADE DE TERAPIA INTENSIVA NEONATAL
}

Karla Maria Carneiro Rolim ${ }^{1}$, Nahana Rebouças Santiago², Tays Lopes Vieira ${ }^{3}$, Marcela Carneiro Sancho ${ }^{4}$, Mirna Albuquerque Frota ${ }^{5}$, Hélène Boulard ${ }^{6}$, Patricia Neveau ${ }^{7}$

Objetivo: conhecer os sentimentos maternos durante a internação do filho na Unidade de Terapia Intensiva Neonatal. Metodologia: estudo exploratório, descritivo e de abordagem qualitativa, realizado na Unidade de Terapia Intensiva Neonatal da MaternidadeEscola Assis Chateaubriand, na cidade de Fortaleza, Ceará, Brasil. Realizada entrevista semiestruturada e oficina nas quais as mães desvelaram sentimentos acerca da hospitalização dos seus filhos por meio de desenhos. Resultados: as mães compreendem a unidade de tratamento intensivo como um lugar importante para a recuperação dos seus filhos. Apesar das dificuldades, estar presente e poder contribuir para sua recuperação é prazeroso e fundamental. Conclusões: para a conscientização das mães acerca da sua contribuição para a recuperação do filho, são imprescindiveis o diálogo e mudanças no olhar e na postura da enfermeira, cujo principal desafio é compartilhar emoções inerentes ao modo de cuidar.

Descritores: Recém-nascido. Mães. Unidade de Terapia Intensiva Neonatal. Cuidados de Enfermagem.

\section{IMAGINARY OF MOTHERS ABOUT CHILD'S HOSPITALIZATION IN NEONATAL INTENSIVE CARE UNIT}

Objective: the aim of study was to know the maternal feelings during the hospitalization of the child in the Neonatal Intensive Care Unit. Method: study is exploratory, descriptive and qualitative approach type, with a qualitative approach, held at the Neonatal Intensive Care Unit of motherhood-School Assis Chateaubriand, in Fortaleza, Ceara, Brazil. Interview and workshop were conducted in which mother's unveiled feelings about the hospitalization of their children through drawings. Results: the mothers understand the intensive care unit as an important place for the recovery of their children. Despite the difficulties, to be present and can contribute to its recovery is pleasurable and fundamental. Conclusions: to the awareness of mothers about their contribution to the child's recovery, the dialogue and changes in the nurse posture are essential. The main challenge to the nurse is to share emotions inherent in the way of care.

Descriptors: Newborn, Mothers. Intensive Care Units, Neonatal. Care. Nursing Care.

IMAGINARIO DE LAS MADRES SOBRE LA HOSPITALIZACIÓN DEL NIÑO EN LA UNIDAD DE CUIDADOS INTENSIVOS NEONATALES Objetivo: el objetivo de satisfacer los sentimientos maternos durante la hospitalización del niño en la unidad de cuidados intensivos neonatales. Método: estudio exploratorios y descriptivos, con un enfoque cualitativo, llevó a cabo en el Neonatal unidad de cuidados intensivos de la maternidad escuela Assis Chateaubriand, en Fortaleza, Ceará, Brasil. Llevó a cabo la entrevista y taller en el que sentimientos desplegado de las madres sobre la hospitalización de sus hijos a través de dibujos. Resultados: las madres entienden la unidad de cuidados intensivos como un lugar importante para la recuperación de sus hijos. A pesar de las dificultades, estar presente y contribuir a su recuperación es placentero y fundamental. Conclusiones: para el conocimiento de las madres sobre su contribución a la recuperación del niño, el diálogo y cambios en la postura de la enfermera son essenciales .El principal desafio de la enfermeira es compartir emociones inherentes a modo de cuidar.

Descriptores: Recién Nacido. Madres. Unidades de Cuidado Intensivo Neonatal. Atención de Enfermería.

1Enfermeira. Pós-Doutora pela Universidade de Rouen/França (CHU-ROUEN). Docente do Curso de Graduação em Enfermagem. Docente Adjunta do Mestrado em Saúde Coletiva da Universidade de Fortaleza e Coordenadora do Mestrado Profissional Tecnologia e Inovação em Enfermagem (UNIFOR). E-mail: karlarolim@unifor.br ${ }^{2,3}$ Enfermeiras. Integrantes do Grupo de Pesquisa Saúde e Qualidade de Vida do Binômio Mãe e Filho. Brasil (UNIFOR/CNPq).

${ }^{4}$ Psicóloga. Especialista em Saúde Mental pela Faculdade Latino Americana de Educação (FLATED). Brasil. marcela.sancho@hotmail.com

${ }^{5}$ Enfermeira. Pós-Doutora pela Universidade Federal da Bahia / Instituto de Saúde Coletiva (ISC). Docente do Curso de Graduação em Enfermagem; do Mestrado em Saúde Coletiva da Universidade de Fortaleza e do Mestrado Profissional Tecnologia e Inovação em Enfermagem (UNIFOR). E-mail: mirnafrota@unifor.br

${ }^{6}$ Enfermeira. Coordenadora de Pesquisa Paramédica do Complexo Hospitalar de Rouen. (CHU-Rouen). França helene.boulard@chu-rouen.fr

7Enfermeira. Coordenadora do Setor de Obstetricia e Neonatologia do Complexo Hospitalar de Rouen. (CHU-Rouen). França. patricianeveau@chu-rouen.fr 


\section{INTRODUÇÃO}

Apesar da relevância da Unidade de Terapia Intensiva (UTIN) para os recém-nascidos prematuros (RNPT) e/ou enfermos, contraditoriamente, essa unidade que deveria zelar pelo bem-estar da criança em todos os seus aspectos, é por excelência um ambiente nervoso, impessoal e até temeroso para aqueles que não estão adaptados às suas rotinas. O ambiente é repleto de luzes fortes e constantes, barulho, mudanças de temperatura, interrupção do ciclo do sono, haja vista a necessidade de repetidas avaliações e procedimentos, acarretando, muitas vezes, desconforto e dor(1).

A internação do RN na UTIN pode significar, para a mãe, gravidade no seu quadro clínico e risco de morte, e representar uma ameaça à integridade emocional materna, causando sofrimento para ela e sua família. O que mais gera impacto nas mães é o contraste entre a fragilidade do filho e a quantidade de aparelhos, sons e tubos conectados a ele $e^{(2)}$. Nesse sentido, o acolhimento aos familiares é fundamental para que as experiências emocionais que ocorrerem nesse periodo sejam compreendidas, aceitas e, assim, o sofrimento dos pais minimizados ${ }^{(3)}$.

O cuidado ao binômio está ligado às formas de estar-com a mãe e o bebê, demonstrando afeto e carinho, valorizando-o, também, nas dimensões técnica e instrumental, tornando o cuidado um momento de troca relacional. Segundo Paterson e Zderad (4.53) "os seres humanos podem relacionar-se como sujeito a objeto e como sujeito a sujeito, isto é, pessoa a pessoa. Ambos os tipos de relação são essenciais para a existência humana genuína".

Conscientes dessa situação que envolve as mães de bebês internados em UTIN, considera-se relevante desenvolver um estudo dessas experiências, sentimentos e expectativas por elas sentidas, baseado em seu imaginário, e propor mudanças na metodologia de uma assistência que demonstre o papel da mãe frente à recuperação e promoção da saúde de seu filho.

O imaginário pode ser definido como a produção de imagens, ideias, concepções, visões de um indivíduo ou de um grupo para expressar sua relação de alteridade com o mundo(5). Portanto, objetivou-se conhecer os sentimentos de mães, durante a internação do seu filho na UTIN e descrever as estratégias humanizadoras da equipe de enfermagem direcionadas ao binômio mãe/filho neste período.

\section{METODOLOGIA}

Pesquisa qualitativa, exploratória e descritiva( ${ }^{(6)}$, realizada na UTIN da Maternidade Escola Assis Chateaubriand (MEAC), na cidade de Fortaleza, Ceará, Brasil, no período de janeiro a março de 2014. Participaram do estudo sete mães de RNPT assistidos na UTIN, convidadas por meio de avisos sobre o estudo e seus objetivos, expostos em locais de fácil acesso como a recepção da Unidade de Neonatologia e Serviço Social.

Após o participante assinar o termo de consentimento livre e esclarecido, foi realizada entrevista semi-estruturada. Logo após, foi conduzida oficina na qual as mães desvelaram sentimentos acerca do processo de hospitalização dos seus filhos em UTIN por meio de desenhos elaborados com uso de cartolina e lápis coloridos. Os desenhos foram analisados por uma psicóloga que utilizou a técnica projetiva house-tree-person ${ }^{(7)}$, e o psicodiagnóstico ${ }^{(8,9)}$. Para análise e interpretação dos dados, optou-se pela análise temática(b). Para tanto, as entrevistas foram transcritas na integra e os dados oriundos desses relatos foram lidos, codificados, e agrupados por semelhança e analisados, emergindo as categorias.

O estudo foi aprovado pelo Comitê de Ética da referida Instituição, sob parecer, n-545.104, respeitando os aspectos éticos e legais da Resolução 466/12 do Conselho Nacional de Saúde ${ }^{(10)}$

\section{RESULTADOS E DISCUSSÃO \\ Conhecendo as mães}

A faixa etária das participantes está compreendida entre 18 a 34 anos. Quanto ao estado civil, a maioria era solteira; quanto à escolaridade, uma tinha ensino fundamental incompleto; uma tinha ensino médio incompleto; quatro haviam concluído o ensino médio e uma concluiu o ensino superior. Cinco eram primíparas e duas secundiparas. Em relação à procedência das mães, seis eram da capital e uma procedia do interior do estado.

\section{Significado do ambiente da UTIN para as mães}

A hospitalização de uma criança pode ser considerada uma fatalidade na vida de uma família. Além do sofrimento causado pela própria doença, a hospitalização em si já é considerada fatigante e causadora de alterações na maioria dos aspectos da vida familiar, incluindo separação dos pais, por tempo indeterminado para acompanhar o tratamento do filho. O longo período de hospitalização do bebê implica mudanças significativas na dinâmica familiar, dentre estas, o abandono de funções e de papéis sociais por parte dos membros da família, dada a necessidade de permanecer junto ao RNPT. Assim, o medo e o sentimento de solidão afetam o equilibrio e os papeis ocupados por cada um dos familiares, 0 que pode precipitar a desestruturação familiar ${ }^{(11)}$

A mãe de um RNPT vivencia um período estressante, do qual emergem inúmeros problemas e preocupações, incluindo o medo frente à situação de fragilidade e risco ao 
qual o filho está exposto; insegurança quanto aos cuidados; ansiedade em relação à doença, tratamento e recuperação, entre outros. O afastamento da criança gera frustração e desapontamento e, conforme a gravidade do quadro clínico, deparam-se com um futuro incerto(2).

O preparo das mães para ver o filho na UTIN é de responsabilidade da enfermeira, sendo assim, antes de entrar na unidade, as mães devem ser orientadas quanto à aparência geral do bebê, conhecer equipamentos e a finalidade ${ }^{(12)}$. A percepção da mãe em relação ao filho na UTIN, e sobre a ambiência da unidade, além do conhecimento acerca da doença, seu tratamento e recuperação: A UTI é para quando nosso bebê está em estado crítico. Quando ele nasceu era muito imaturuzinho não tinha sete meses direito, ficou intubado com aparelho que respira por ele, depois ele foi para um CPAP, agora ele está no HOOD, com o ar circulando ao redor da cabeça dele (MI). É para ajudar no desenvolvimento da criança, para quando o neném nascer prematuro ele amadurecer o pulmão ou algum outro órgão interno; UTIN é onde tem todo o material necessário para eles (M7).

As mães compreendem a UTIN como um lugar importante na recuperação dos bebês sob cuidados especiais. As mães detinham informações acerca da doença/tratamento dispensado ao filho e assumem postura ativa nos cuidados ao bebê e o estabelecimento do vínculo afetivo. A presença da mãe ao lado do filho hospitalizado traz benefícios para ambos, pois, além de representar segurança e conforto, possibilita prevenir efeitos traumáticos ${ }^{(1)}$.

\section{Percepções das mães acerca do acompanhamento e participação ativa na recuperação do seu filho na UTIN}

É relevante a presença materna na UTIN e na sua participação nos cuidados ao filho hospitalizado, não só para o estabelecimento do vínculo afetivo mãe/filho, mas, para a redução do estresse causado pela hospitalização e o preparo para o cuidado à saúde no domicílio(13). O fato de não poder pegar o bebê no colo, aconchegá-lo e embalá-lo é frustrante para a mãe. Este ambiente tão tecnicista tem o objetivo de propiciar tempo para que os cuidadores permaneçam perto do paciente, olhando-os, tocando-os, dialogando e até velando seu sono tranquilo, enquanto monitores fornecem os dados vitais ${ }^{(14)}$

Mesmo quando já é possivel tocá-lo e acariciá-lo dentro da incubadora, muitas mães se amedrontam diante dessa situação. Esse medo se justifica pela autoestima afetada, pelo ambiente da UTIN e pela falta de autoconfiança na capacidade de criar o filho. Ao serem bem acolhidas e orientadas, entretanto, as mães passam a reconhecer os benefícios da UTIN, embora percebam que o processo de separação entre mãe/filho é previsivel, como ressaltado em suas falas: Tenho que estar do lado. Ontem tive a prova do quanto é importante, porque meu esposo veio e a gente nunca tinha colocado a mão nela. Ontem colocamos e hoje de manha quando a vi já estava sem o aparelho, respirando sozinha (M2); Acompanhar ele direto é bom demais (risos). Ficar longe é ruim. Acho que sou a experiência melhor para ele. Sei que estão cuidando muito bem, mas ele precisa do calor da mamãe para ir mais para frente (M4); É complicado viu? Não poder fazer nada. Ajudo em estar presente, em conversar com ele [...] (M5); É importante ele sentir que estou presente. Meu leite é importante na recuperação dele. Sinto que deixando meu leite é como se eu tivesse com ele o tempo todo (M7)

Os benefícios da participação materna são reconhecidos em estudos que demonstraram efeitos clínicos, tais como a redução da dependência do ventilador, melhora do ganho ponderal, início da sucção não nutritiva mais precocemente, auto-regulação, melhora neurocomportamental, redução do tempo de hospitalização e dos custos do cuidado. Assim, a mãe entender que sua presença é percebida pelo filho a estimula a permanecer próxima ao neonato. Essa participação é necessária para o desenvolvimento psicoafetivo da criança e para o desenvolvimento de seus papéis sociais como mães/pais também "prematuros"(15).

As mães desvelam que para o surgimento da maternagem, ela desenvolve comportamentos de aproximação, através do vínculo e das manifestações interacionais. É preciso que ela, ao se aproximar do filho, mesmo que "diferente", sorria, faça gestos faciais, abrace, acaricie, beije, cantarole, contemple-o prolongadamente; estas atitudes são consideradas indícios de vínculos.

Apesar do contexto de dificuldades no qual estão inseridas, o fato de estarem presentes e contribuírem na recuperação de seus filhos é algo prazeroso e fundamental para ambas as partes. O encontro ocorrerá se tanto um quanto o outro estiverem disponíveis, querendo que ele ocorra. Dar-se-á de forma efetiva, ou seja, com qualidade, se os seres envolvidos mostrarem sua singularidade. Segundo Paterson e Zderad(4), é importante considerar a amplitude dos encontros humanos, que vão do trivial ao extremamente significante.

\section{Vivência dialógica durante a oficina e o desvelar dos sentimentos maternos através dos desenhos}

O ambiente do encontro foi alvo de dedicada atenção. Foram utilizados caprichosos objetos de decoração, como corações de papéis coloridos; jarros pequenos com flores, lembrando jardins por onde as mães pudessem passear com suas emoções; balões coloridos, cheios de sonhos; corações pequeninos de cartolina brilhante e de cores diferentes a enfeitar as paredes ao redor. Estes preparativos foram 
relevantes para buscar, acolher e brindar as participantes com visões delicadas e agradáveis do ambiente dos encontros. Então, o estar com elas, foi em um espaço existente, naqueles momentos de interação. O diálogo com as mães foi estimulado pela consciência que elas tinham de sua experiência no espaço conhecido da UTIN, favorecendo seu bem-estar.

A oficina foi iniciada com a realização de uma dinâmica chamada "Teia da Amizade", onde cada integrante, incluindo as pesquisadoras, seguravam uma ponta do novelo de lã e apresentavam-se a si mesmas e a pessoa ao lado, de forma descontraída, embalada por uma melodia alegre; aos poucos, foram apresentando-se umas as outras. Logo após, as mães foram orientadas a utilizarem papeis, lápis e canetinhas coloridas para externarem seus sentimentos sobre as vivencias em UTIN. A elaboração dos desenhos foi embalada por uma música suave ao fundo, trazendo à flor da pele as emoções por elas vivenciadas.

Ao término do encontro, os desenhos eram recolhidos e as mães acalentadas com olhares de ternura, palavras reconfortantes e gestos cuidadosos como consolo sobre suas dúvidas e anseios. Para findar o encontro, foi oferecido um lanche às mães, ressaltando a partilha de sentimentos positivos e de esperança quanto a recuperação dos seus filhos.

Os desenhos e a participação das mães nos encontros foram motivos de diálogo com a psicóloga, que, após sua reflexão sobre os desenhos, posicionou-se: percebe-se alguns aspectos comuns que estão relacionados tanto à situação vivenciada pelas mães acerca da internação de seus filhos quanto por questões envolvidas em torno da maternidade.

FIGURA - Desenhos relativos à internação do filho, segundo a representação das mães. Fortaleza, 2014.

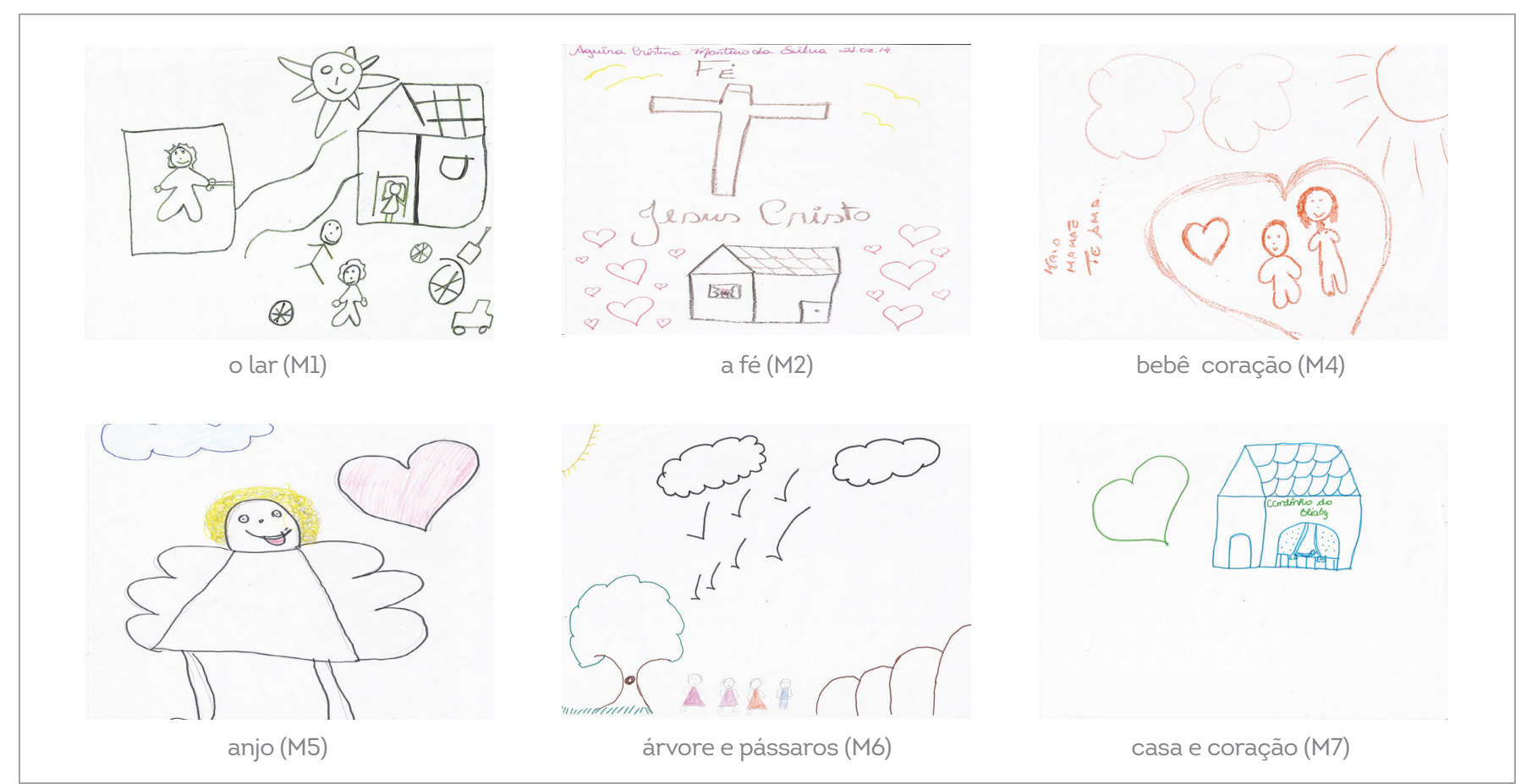

Fonte: Santiago, Vieira, Rolim, 2014

O Lar, analisa a psicóloga, aparece simbolizado pela figura da casa quase na totalidade dos desenhos, o que pode representar o desejo das mães de retornar a sua função familiar e materna levando consigo o novo membro(7), uma vez que a internação dos filhos acarretou uma interrupção ou minimização do papel de "gestora" do lar.

O desenho de bebês dentro de algumas casas e próximos à janela aponta o sentimento de proteção do lar e a esperança de terem seus filhos sob os seus cuidados, além do desejo de apresentar aos outros o fim das angústias e incertezas e do sentimento de passividade trazido pela internação(8,9). A esperança pelo restabelecimento da saúde dos filhos, também se encontra representada pelo aspecto religioso, como o desenho da cruz e os escritos "Fé" e "Jesus Cristo", bem como o desenho de estradas e de crianças brincando, simbolizando uma vida saudável(7).

A religião é um aspecto presente no contexto da internação e da doença. A reprodução desta ideia pode ser encontrada no desenho do bebê simbolizado como um anjo. Para muitos, o nascimento de uma criança resume a chegada do amor incondicional. O bebê tem a função de trazer paz e alegria e, a partir da sua "chegada", nasce ou se reconstrói uma família(16).

Os corações desenhados próximos às casas retomam 
questões apontadas anteriormente como a função do bebê em um lar e este como local de proteção e amor, apontando o desejo do fim da internação. A escolha de cores claras e vibrantes dos desenhos e dos cenários de casas em meio a árvores, sol e pássaros podem refletir a esperança e a expectativa de uma vida cheia de amor, saúde e alegrias, almejada com a maternidade ${ }^{(7,8)}$.

A acreditação, segurança na equipe e a satisfação com o andamento do tratamento podem ter propiciado desenhos tão cheios de esperança, demonstrando o envolvimento e acolhimento da equipe com os familiares e um atendimento humanizado. A enfermeira atenta aos chamados da mãe, procura compreendê-la, não assumindo uma postura crítica, mas de agente transformador, transmitindo a ela uma visão realista, favorecendo a participação na recuperação da saúde do seu filho e assim resgatando seu papel de mãe $e^{(17)}$.

\section{CONCLUSÃO}

As mães sentem-se angustiadas com o sofrimento de seus filhos no ambiente da UTIN. No entanto, sobressaem fatores atenuantes como a confiança no trabalho da equipe aliado à esperança e otimismo quanto à recuperação dos bebês. O choque pela hospitalização de um bebê prematuro pode, de certo, ser atenuado com a oportunidade que essa mãe tem, ou não, de participar, de alguma forma, dos cuidados de seu filho.

A experiência nas oficinas caracterizou-se como exercício da intersubjetividade, por meio dos desenhos, pois a interação possibilitou a compreensão do significado para as mães sobre o processo de internação dos filhos prematuros na UTIN. E, para a conscientização das mães acerca do seu papel na contribuição para a recuperação do filho, tornam-se imprescindiveis mudanças na postura da enfermeira, cujo principal desafio é compartilhar emoções, inerentes ao modo de cuidar.

O vínculo afetivo do binômio mãe/filho evidenciou-se nos momentos de interação e na integração dos conteúdos sob uma visão interdisciplinar, por sua vez, considerado primordial na recuperação do bebê. Nesse sentido, o toque, o calor humano e o carinho ofertado pela mãe culminaram na afirmativa de que não seria possivel a cura completa do filho sem esses elementos essenciais.

\section{REFERÊNCIAS}

1. Perlin DA, Oliveira SM, Gomes GC. A criança na unidade de terapia intensiva neonatal: impacto da primeira visita da mãe. Rev Gaúcha Enferm. 2011;32(3):458-64

2. Costa R, Padilha MI, Monticelli M. Produção de conhecimento sobre os cuidados ao recém-nascido em UTI Neonatal: contribuição da enfermagem brasileira. Rev Esc Enferm USP. 2010; 44(1): 199-204.

3. Rolim KMC, Cardoso MVLML. A interação enfermeira-recém-nascido durante a prática de aspiracão orotraqueal e coleta de sangue. Rev Esc Enferm USP. 2006:40(4):515-23.

4. Paterson JG, Zderad LT. Humanistic nursing. New York (NY): National League for Nursing, 1988.

5. Silva LA, Gomes AMT, Oliveira DC, Souza MGG. Social representations of aging in institutionalized psychiatric patients. Esc Anna Nery. 2011. [cited 2016 Mar 14]; 15(1). Available from: http://www.scielo.br/scielo. php?script=sci_arttextEpid=S1414-81452011000100018.

6. Minayo MCS. Análise qualitativa: teoria, passos e fidedignidade. Ciência \& Saúde Coletiva. 2012; 17(3):621-6.

7. Buck JN. The house-tree-person technique - HTP. São Paulo: Vetor, 2009.

8. Cunha JA. Psicodiagnóstico. 5 ed. Porto Alegre; Artmed, 2007.

9. Amelang M, Schmidt-Atzert L. Psychologische diagnostik und intervention. Berlin: Springer, 2006.
10. Brasil. Ministério da Saúde. Conselho Nacional de Saúde. Comissão Nacional de Ética em Pesquisa - CONEP. Resolução 466/12. Dispõe sobre as diretrizes e normas regulamentadoras de pesquisas envolvendo seres humanos. Brasilia, DF, 2012.

11. Araújo VKS, Oliveira DKMA, Oliveira FCM. Neonato hospitalizado em uma unidade de terapia intensiva neonatal: experiência vivenciada pelos familiares. Rev Bras Ci Saúde. 2013; 11(36): 68-76.

12. Rolim KMC, Cruz EMF, Maia LA. A importância do vinculo mãe/filho na atenção humanizada ao recém-nascido prematuro: percepção materna. 2012. Rev Tendên Enferm Profis. 2012; 5(2): 779-83.

13. Ferreira FR, Callado LM. O afeto do toque: benefícios nos recémnascidos. Rev Med Saúde Brasilia. 2013; 2(2):112-9.

14. Martins EMA, Lopes MF, Mariano AA, Silva LES, Rolim KMC, Frota MA. Os agravos no desenvolvimento neurocomportamental do recém-nascido prematuro: ênfase no manuseio. ReTEP. Rev Tendên Enferm Profis. 2015; 7(2): 1481-5.

15. Fraga TF, Amante LN, Anders JC, Padilha ICS, Henckemaeir L, Costa R. Bock LF. Percepção das mães sobre o processo comunicacional na unidade de terapia intensiva neonatal. Rev Eletr Enf. 2009; 3(11): 612-9.

16. Godinho MFN. Manual prático de avaliação do HTP (casa-árvore-pessoa) e familia. Casa do Psicólogo: São Paulo, 2012.

17. Rolim KMC, Cardoso MVLML. O discurso e a prática do cuidado ao recém-nascido de risco: refletindo sobre a atenção humanizada. Rev. Latino-Am Enfermagem. 2006; 14 (1): 85-92. 